\title{
Contribution of mutations in the cytochrome P450 14 $\alpha$-demethylase (Erg11p, Cyp51p) to azole resistance in Candida albicans
}

\author{
Patrick Marichal, ${ }^{1,5}$ Luc Koymans, ${ }^{2}$ Staf Willemsens, ${ }^{1}$ Danny Bellens, ${ }^{1}$ \\ Peter Verhasselt, ${ }^{3}$ Walter Luyten, ${ }^{4}$ Marcel Borgers, ${ }^{5}$ \\ Frans C. S. Ramaekers, ${ }^{5}$ Frank C. Odds ${ }^{1}$ and Hugo Vanden Bossche ${ }^{1}$
}

Author for correspondence: Patrick Marichal. Tel: +32 146031 97. Fax: +32 14605403. e-mail: pmaricha@janbe.jnj.com

1,2,3,4 Department of Anti-
infectives Research1,
Center for Molecular
Design', Department
of Biotechnology' and
Department of
Functional Genomics ${ }^{4}$,
Janssen Research
Foundation,
Turnhoutseweg 30,
B2340 Beerse, Belgium
5 Department of
Molecular Cell Biology
and Genetics,
University of
Maastricht, The
Netherlands

The cytochrome P450 14 $\alpha$-demethylase, encoded by the ERG11 (CYP51) gene, is the primary target for the azole class of antifungals. Changes in the azole affinity of this enzyme caused by amino acid substitutions have been reported as a resistance mechanism. Nine Candida albicans strains were used in this study. The ERG11 base sequence of seven isolates, of which only two were azole-sensitive, were determined. The ERG11 base sequences of the other two strains have been published previously. In these seven isolates, 12 different amino acid substitutions were identified, of which six have not been described previously (A149V, D153E, E165Y, S279F, V452A and G465S). In addition, 16 silent mutations were found. Two different biochemical assays, subcellular sterol biosynthesis and $\mathrm{CO}$ binding to reduced microsomal fractions, were used to evaluate the sensitivity of the cytochromes for fluconazole and itraconazole. Enzyme preparations from four isolates showed reduced itraconazole susceptibility, whereas more pronounced resistance to fluconazole was observed in five isolates. A three-dimensional model of $C$. albicans Cyp51p was used to position all 29 reported substitutions, 98 in total identified in $\mathbf{5 3}$ sequences. These 29 substitutions were not randomly distributed over the sequence but clustered in three regions from amino acids 105 to 165, from 266 to 287 and from 405 to 488, suggesting the existence of hotspot regions. Of the mutations found in the two $\mathbf{N}$-terminal regions only $\mathrm{Y} 132 \mathrm{H}$ was demonstrated to be of importance for azole resistance. In the Cterminal region three mutations are associated with resistance, suggesting that the non-characterized substitutions found in this region should be prioritized for further analysis.

Keywords: itraconazole, fluconazole, resistance, $\operatorname{Erg} 11 \mathrm{p}$, modelling

\section{INTRODUCTION}

Partly as a result of the AIDS epidemic, the incidence of fungal infections has increased during the last decade. Oropharyngeal candidiasis is the most common fungal infection in AIDS patients. Only a few classes of antifungal compounds are available to treat these infections. One important class consists of inhibitors of ergosterol biosynthesis (EBI). Several enzymes in this pathway are targets for commercialized antifungals,

The GenBank accession numbers for the sequences reported in this paper are AF153844-AF153850. such as squalene epoxidase, inhibited by the allylamines, $\Delta^{14}$-reductase and $\Delta^{8,7}$-isomerase, both inhibited by the morpholines, and cytochrome P450s catalysing $14 \alpha-$ demethylation and $\Delta^{22}$-desaturation, inhibited by the azoles. A combination of factors such as the fungistatic nature of the inhibition of Candida albicans observed for azole compounds, impaired host immune responses in infected patients, long treatment periods and use of low antifungal doses, creates favourable breeding conditions for mutation and selection of less susceptible isolates (Cartledge et al., 1997).

Over the last 5 years multiple biochemical studies have been published to elucidate the underlying causes of 
azole resistance in pathogenic fungi. These studies resulted in a series of reviews dedicated to this subject (Bodey, 1997; De Muri \& Hostetter, 1995; Denning et al., 1997; Dupont, 1995; Frosco \& Barrett, 1998; Hartman \& Sanglard, 1997; Johnson \& Warnock, 1995; Joseph-Horn \& Hollomon, 1997; Marichal \& Vanden Bossche, 1995; Odds, 1998; Rex et al., 1995; Sanglard et al., 1998a; Vanden Bossche, 1997; Vanden Bossche et al., 1994, 1998; White et al., 1998). Several mechanisms have been identified that contribute to azole resistance. Probably the most common mechanism is to effect a diminution in the concentration of active compound at the target site. In the majority of cases studied recently, this was the result of overexpression of efflux pumps. So far, two types of efflux transporters have been reported in resistant isolates. The ATPbinding-cassette type (ABC transporters; e.g. CDR1 and $C D R 2$ ) can export a wide variety of azoles and unrelated chemicals (Kolaczkowski \& Goffeau, 1997), and the socalled 'major facilitators', (e.g. CaMDR1, previously described as $B E N^{r}$ ) with a much narrower substrate spectrum (Sanglard et al., 1995).

The second way in which fungi achieve effective resistance to azoles is to circumvent or compensate for the toxic consequences of the changes in sterol composition. Azole-induced growth inhibition results from both the depletion of sterol molecules able to perform some sparking hormonal function (Rodriguez et al., 1985), e.g. ergosterol, and coincidental accumulation of membrane-disturbing 14-methylated precursors. As well as ergosterol, sufficient quantities of 14-methylfecosterol can also fulfil this sparking function. (Watson et al., 1989). Accumulation of 14-methylfecosterol is achieved if cells are deficient in $\Delta^{8,7}$ isomerase and or $\Delta^{5,6}$ desaturase. This effect has been described in an azoleresistant C. albicans isolate (Kelly et al., 1997) as well as in Saccharomyces cerevisiae (Bard et al., 1993).

A third general type of mechanism for azole resistance involves changes at the level of the antifungal target. The primary target for the azole class of antifungals is the cytochrome-P450-catalysed $14 \alpha$-demethylation of ergosterol precursors. This enzyme is encoded by ERG11 (also described as ERG16, CYP51). Overexpression of this enzyme, induced either by enhanced transcription or by gene or chromosomal amplification, results in a decreased sensitivity for this class of antifungals (Marichal et al., 1997; Doignon et al., 1993). Point mutations in Erg11p [suggested by biochemical data (Vanden Bossche et al., 1990) or by sequence analysis], such as $\mathrm{Y} 132 \mathrm{H}$ (tyrosine 132 is replaced by a histidine; Sanglard et al., 1998b), T315A (threonine 315 replaced by alanine; Lamb et al., 1997) or R476K (arginine 476 replaced by lysine; White, 1997), have been shown to decrease the affinity of the target for an azole. Numerous publications have listed other Erg11p mutations, but unfortunately the effect of the mutation on azole sensitivity was not always tested.

In this study, we sequenced the ERG11 gene from a selection of five azole-resistant isolates and two sensitive isolates and evaluated the effects of amino acid substitutions on subcellular sterol biosynthesis and azole sensitivity. Computer modelling and sequence analysis were used to position the mutations found in the 3D model available and to predict their possible importance for resistance.

\section{METHODS}

Strains, media and compounds. Nine strains of Candida albicans were used in this study. Two of them, ATCC 28516 and ATCC 44858, were extensively used in previous biochemical studies (Vanden Bossche et al., 1980) and were azolesensitive. The seven other strains were azole resistant: NCPF 3363 (Smith et al., 1986) was isolated from a patient suffering from chronic mucocutaneous candidiasis (CMC); J913004/I was isolated in France from an AIDS patient; B59626 and B59630 were sequential isolates from an AIDS patient in Germany, strains C40 and C26 were isolated from AIDS patients with oropharyngeal candidiasis and maintained at the Institute of Microbiology, Centre Hospital Universitaire Vaudois, Switzerland (Sanglard et al., 1995); strain 6406/8 was a spontaneous, laboratory-derived polyene-resistant mutant of strain 6406 and was obtained from Dr D. Kerridge, University of Cambridge. The identity of the isolates as C. albicans was confirmed by standard procedures. Yeasts were maintained as glycerol stocks at $-80{ }^{\circ} \mathrm{C}$. The inocula for each individual experiment were prepared from these glycerol stocks to minimize the possible influences of genotypic or phenotypic instability. Itraconazole (Janssen) and fluconazole (Pfizer) were dissolved and diluted in DMSO.

MIC determination. MICs were determined spectrophotometrically by a broth microdilution method (Odds et al., 1995) based on the NCCLS M27A protocol (National Committee for Clinical Laboratory Standards, 1995). In brief, cells were inoculated in RPMI buffered to $\mathrm{pH} 7.0$ with $1.65 \mathrm{M}$ MOPS. Results were read after $48 \mathrm{~h}$ at $37^{\circ} \mathrm{C}$ in a microplate reader (model 3550; Bio-Rad). The MIC was the lowest concentration that inhibited growth by more than $50 \%$; this end point showed the best reproducibility and correlation with results from the NCCLS broth macrodilution method. Quality control yeasts Candida krusei ATCC 6258 and Candida parapsilosis ATCC 22019 were tested in parallel and were inhibited at MICs in the correct ranges for the antifungals tested (National Committee for Clinical Laboratory Standards, 1995).

Sterol synthesis by subcellular fractions. To prepare the subcellular fractions, the C. albicans isolates were grown for $8 \mathrm{~h}$ in static culture and then for $8 \mathrm{~h}$ in a reciprocating shaker set at 100 strokes $\mathrm{min}^{-1}$ in $200 \mathrm{ml} \mathrm{PYG}{ }_{2}$ medium $\left(\mathrm{l}^{-1}: 10 \mathrm{~g}\right.$ polypeptone, $10 \mathrm{~g}$ yeast extract, $40 \mathrm{~g}$ glucose) in $500 \mathrm{ml}$ Erlenmeyer flasks at $30^{\circ} \mathrm{C}$. This method yields cells in the late exponential phase. Cells were collected by centrifugation at $1500 \mathrm{~g}$, washed and resuspended at a density of $10^{9}$ cells $\mathrm{ml}^{-1}$ in cold homogenization buffer containing $0 \cdot 1 \mathrm{M}$ potassium phosphate buffer, $30 \mathrm{nM}$ nicotinamide, $5 \mathrm{mM} \mathrm{MgCl}_{2}, 5 \mathrm{mM}$ reduced glutathione and $1 \mathrm{mM}$ PMSF. Cells were broken in a $350 \mathrm{ml}$ Bead-Beater receptacle (Biospec Products) filled with $200 \mathrm{~g}$ prechilled acid-washed glass beads (diam. 0·40-0 45 $\mathrm{mm}$ ) by three cycles of $1 \mathrm{~min}$ agitation with intermittent cooling. To prevent heating of the samples, the outer jacket of the Bead-Beater was filled with ice-cold water. The homogenate was differentially centrifuged at $4{ }^{\circ} \mathrm{C}$ in a Sorvall SS34 rotor, first for $5 \mathrm{~min}$ at $1500 \mathrm{~g}$ and then for $20 \mathrm{~min}$ at $8000 \mathrm{~g}$. The protein content of the $S_{8000}$ supernatant fraction was 
measured according to the Bio-Rad method using bovine serum albumin as a standard (Bradford, 1976). To measure sterol biosynthesis, $900 \mu \mathrm{l}$ of the resultant $S_{8000}$ fraction was added to $100 \mu \mathrm{l}$ cofactor buffer to achieve final concentrations of $1 \mu \mathrm{M}$ NADP, $1 \mu \mathrm{M}$ NAD, $3 \mu \mathrm{M}$ glucose 6-phosphate, $5 \mu \mathrm{M}$ ATP, $2 \mu \mathrm{M} \mathrm{MnCl}, 3 \mu \mathrm{M} \mathrm{MgCl}_{2}$ and $0 \cdot 25 \mu \mathrm{Ci}\left[{ }^{14} \mathrm{C}\right]-$ mevalonic acid. One microlitre of inhibitor stock solution and/or DMSO was added to the incubation tubes prior to the addition of the $S_{8000}$ extract. Tubes were incubated for $2 \mathrm{~h}$ in an orbital New Brunswick shaker set at 300 r.p.m. at $30^{\circ} \mathrm{C}$. Reactions were stopped by the addition of $1 \mathrm{ml} 15 \% \mathrm{KOH}$ dissolved in $90 \%$ ethanol and were saponified for $1 \mathrm{~h}$ at $84{ }^{\circ} \mathrm{C}$. Non-saponifiable lipids were extracted with $3 \mathrm{ml}$ n-heptane. Heptane extracts were then dried with a stream of $\mathrm{N}_{2}$ and sterols were separated by TLC as described previously (Vanden Bossche et al., 1992). All experiments were repeated at least three times with different cell extracts.

Spectrophotometric analysis of cytochrome P450. Microsomes were isolated from C. albicans as described previously (Vanden Bossche et al., 1986). In summary, C. albicans cells, grown in semianaerobic conditions, were harvested by centrifugation, then washed and resuspended in ice-cold $0.65 \mathrm{M}$ mannitol. All subsequent steps were done at $4{ }^{\circ} \mathrm{C}$. PMSF was added to a concentration of $1 \mathrm{mM}$. Then the suspension was immediately homogenized in a Bead-Beater as described above. The homogenate was differentially centrifuged for $5 \mathrm{~min}$ at $1500 \mathrm{~g}, 20 \mathrm{~min}$ at $10000 \mathrm{~g}$ and $1 \mathrm{~h}$ at $100000 \mathrm{~g}$. The pellet thus obtained was resuspended in $0.05 \mathrm{M}$ potassium phosphate buffer containing 0.01 M EDTA ( $\mathrm{pH} 7 \cdot 4$ ) and the suspension was recentrifuged for $1 \mathrm{~h}$ at $100000 \mathrm{~g}$ (Vanden Bossche et al., 1986). The final pellet was resuspended in $0 \cdot 1 \mathrm{M}$ potassium phosphate buffer ( $\mathrm{pH} 7 \cdot 4)$. The P-450 content and the effects of azoles on the interaction of $\mathrm{CO}$ with the reduced haem iron of P-450 were measured as described previously (Vanden Bossche et al., 1986).

PCR amplification and sequence analysis of the C. albicans ERG11 gene. To amplify the ERG11 gene encoding the cytochrome P450 14 $\alpha$-demethylase we used 5'-TAATACGACTCACTATAGGGAAGATCATAACTCAATATGGCTATTGTTG-3' composed of a 19 bp T7 sequence and nucleotides 131-161 from the Lai \& Kirsch (1989; accession number X13296) sequence, including the first four codons of the ORF, as sense primer and 5'-ATTTAGGTGACACTATAGGAAAGTTGCCGTTTTATTAAAACATAC-3' composed of the SP6 sequence (18 bp) and the 1724-1750 region of the published sequence surrounding the stop codon of the ORF as antisense primer. Heat-activatable AmpliTaq Gold ( 0.5 units; Perkin Elmer) was used with $2.5 \mathrm{mM} \mathrm{MgCl}_{2}$. DNA from all C. albicans strains was prepared by the Qiagen DNA extraction method according to the procedures of the manufacturer with zymolyase $\left(60 \mathrm{U} ; 5000 \mathrm{Ug} \mathrm{g}^{-1}\right.$; Arthrobacter luteus; Seikagaku Kogyo) used as the cell-wall-degrading enzyme. The PCR parameters were $10 \mathrm{~min}$ at $94^{\circ} \mathrm{C}$ to activate the polymerase and then 30 cycles of 1 min annealing at $60^{\circ} \mathrm{C}$, 2 min elongation at $72{ }^{\circ} \mathrm{C}$ and 1 min denaturation at $92^{\circ} \mathrm{C}$. After the reaction, the $1657 \mathrm{bp}$ PCR product was purified with a Qiagen PCR cleanup kit and a sample was separated on a $1 \%$ agarose gel in $0.5 \times \mathrm{TBE}$ with Boehringer molecular mass standard VI. The $1657 \mathrm{bp}$ amplification products from the different isolates were sequenced on both strands using the PCR primers and internal primers every $300 \mathrm{bp}$ as follows: (name, sequence, nucleotide numbering according to Lai \& Kirsch,1989; accession number X13296, direction) Ca ERG1101, TTAGGTCCAAAAGGTC, 432, sense; Ca ERG11-02, CATGACCTTTTGGACC, 451, antisense; Ca ERG11-03, GACCGTTCATTTGCTC, 787, sense; Ca ERG11-04,
GAGCAAATGAACGGTC, 802, antisense; Ca ERG11-05, ATTCTTATGGGTGGTC, 1057, sense; Ca ERG11-06, GCAGAAGTAGAAGCAG, 1097, antisense; Ca ERG11-07, TCTCCAGGTTATGCTC, 1360, sense; Ca ERG11-08, CCCATCTAGTTGGATC, 1439, antisense). Primers were designed by visual inspection of the sequence for stretches of 16-18 nucleotides of normal composition (40-60\% GC, no palindromes, no homopolymeric stretches). Primers were ordered from Eurogentec (Seraing) and were synthesized according to the $\beta$-cyanoethylphosphoramidite method. Sequencing reactions were performed with the ABI Prism BigDye Terminator Cycle Sequencing Ready Reaction Kit, used according to the instructions of the manufacturer (PerkinElmer), except that half of the volume of terminator mix was replaced by HalfTerm (GenPak). Sequencing reactions were run on an Applied Biosystems 377 XL DNA sequencer (PerkinElmer).

Sequences were assembled from the individual runs into single contig sequences by means of Sequencher software (Gene Codes Corporation). Ambiguity positions were scored by setting the threshold as low as $30 \%$ (i.e. secondary peaks at $30 \%$ of primary peak results in ambiguity call) and by inspecting all of the ambiguity calls on all available readings.

\section{RESULTS \\ MIC determination}

The MIC values obtained with the NCCLS compatible methodology confirmed the previously reported susceptibility of the different strains, except for isolate $6406 / 8$. For both sensitive ATCC reference strains, MIC values of $0 \cdot 13 \mu \mathrm{g} \mathrm{ml}^{-1}$ were found for fluconazole and $0.016 \mu \mathrm{g} \mathrm{ml}^{-1}$ or lower for itraconazole (Table 1). In these test conditions isolate $6406 / 8$ was also inhibited at low concentrations of both fluconazole and itraconazole, but showed a pronounced trailing growth effect. Complete inhibition was seen in this spontaneous laboratory mutant only at a concentration of $32 \mu \mathrm{g}$ fluconazole $\mathrm{ml}^{-1}$ and $2 \mu \mathrm{g}$ itraconazole $\mathrm{ml}^{-1}$. All other strains had high MIC values for fluconazole $(>32 \mu \mathrm{g}$ $\left.\mathrm{ml}^{-1}\right)$ and itraconazole $\left(\geqslant 0.5 \mu \mathrm{g} \mathrm{ml}^{-1}\right)$ and as such fell either at the high end of the dose-dependent sensitivity range or in the resistant range, according to the NCCLS breakpoints. The difference in ratios of MIC values obtained for fluconazole versus itraconazole for the isolates studied (Table 1) suggests that resistance to fluconazole was more pronounced in the isogenic strains B59626 and B59630, and in isolates J913004/1 and C40. In the case of this last isolate it was shown that overexpression of CaMDR1, a major facilitator pump that takes fluconazole and not itraconazole as a substrate, contributed to this fluconazole resistance (Sanglard et al., 1995).

\section{ERG11 sequence analysis}

Both strands of the coding region of the ERG11 genes of all eight strains were sequenced and compared to the Lai \& Kirsch (1989) sequence. Each strain examined carried from 9-12 nucleotide changes of which at least one and up to four resulted in an amino acid substitution relative 
Table 1. Amino acid polymorphisms found in sensitive and resistant isolates together with MIC values, sensitivity of the subcellular sterol biosynthesis and cytochrome P450 CO binding for fluconazole and itraconazole

Results shown are from representative experiments. Each experiment was repeated at least three times; variation was less than $10 \%$.

\begin{tabular}{|c|c|c|c|c|c|c|c|c|c|c|c|c|}
\hline \multirow[t]{3}{*}{ Strain } & \multicolumn{3}{|c|}{$\operatorname{MIC}\left(\mu \mathrm{g} \mathrm{ml}^{-1}\right)$} & \multicolumn{5}{|c|}{ Subcellular sterol biosynthesis } & \multicolumn{3}{|c|}{$\begin{array}{l}\text { Cytochrome P450 CO } \\
\text { displacement }\left(\mathrm{IC}_{50} \mathrm{nM}\right)^{*}\end{array}$} & \multirow{3}{*}{$\begin{array}{c}\text { Amino acid point } \\
\text { mutation }(\mathrm{xNNNx} / \mathrm{y}) \dagger\end{array}$} \\
\hline & \multirow[t]{2}{*}{ Fluconazole } & \multirow[t]{2}{*}{ Itraconazole } & \multirow[t]{2}{*}{ Ratio } & \multicolumn{2}{|c|}{ Fluconazole } & \multicolumn{2}{|c|}{ Itraconazole } & \multirow[t]{2}{*}{ Ratio } & \multirow[t]{2}{*}{ Fluconazole } & \multirow[t]{2}{*}{ Itraconazole } & \multirow[t]{2}{*}{ Ratio } & \\
\hline & & & & $\begin{array}{l}\mathrm{IC}_{50} \\
(\mathrm{nM})\end{array}$ & $\begin{array}{c}{[\% \mathrm{C}] 1000} \\
\mathrm{nM} \neq\end{array}$ & $\begin{array}{l}\mathrm{IC}_{50} \\
(\mathrm{nM})\end{array}$ & $\begin{array}{c}{[\% \mathrm{C}] 100} \\
\mathrm{nM} \neq\end{array}$ & & & & & \\
\hline ATCC 28516 & $0 \cdot 13$ & $\leqslant 0 \cdot 008$ & $>16$ & 41 & 5 & 44 & 2 & $0 \cdot 9$ & 145 & 38 & $3 \cdot 9$ & F72F/L, E266D [10] \\
\hline ATCC 44858 & $0 \cdot 13$ & $0 \cdot 016$ & 8 & 42 & 3 & 37 & 2 & $1 \cdot 1$ & 203 & 36 & $5 \cdot 6$ & D153E, E266D [10] \\
\hline B59626 & $>64$ & 1 & $>64$ & 87 & 5 & 33 & 1 & $2 \cdot 6$ & 270 & 40 & $6 \cdot 8$ & D116E, K128T, A149V [8] \\
\hline B59630 & 64 & 0.5 & 128 & 65 & 4 & 21 & 5 & $3 \cdot 1$ & 530 & 54 & $9 \cdot 8$ & D116E, K128T, A149V [8] \\
\hline NCPF 3363 & 32 & 2 & 16 & 220 & 21 & 92 & 48 & $2 \cdot 4$ & 221 & 55 & $2 \cdot 4$ & Y132H, S279S/F, G465G/S [8] \\
\hline J913004/1 & 64 & 1 & 64 & 172 & 17 & 22 & 7 & $7 \cdot 8$ & & $\begin{array}{c}\text { Insufficient } \\
\text { P450\$ }\end{array}$ & & D116E, K128T, V452A, G464S [8] \\
\hline $6406 / 8$ & $\leqslant 0 \cdot 032$ & $\leqslant 0 \cdot 008$ & & 90 & 19 & 14 & 14 & $6 \cdot 4$ & & $\begin{array}{l}\text { Insufficient } \\
\text { P450\$ }\end{array}$ & & E165Y [7] \\
\hline $\mathrm{C} 26$ & $>128$ & $>2$ & & 4880 & 78 & 20 & 24 & 244 & 3080 & 30 & 103 & D116E, Y132H, S405F [8] \\
\hline $\mathrm{C} 40$ & 128 & 1 & 128 & 378 & 37 & 34 & 19 & 11 & 5030 & 44 & 114 & Y132Y/H, G464S, R467K [9]\| \\
\hline
\end{tabular}

* Results obtained with $0 \cdot 1 \mathrm{nmol}$ cytochrome $\mathrm{P} 450 \mathrm{ml}^{-1}$ in the cuvette.

$\dagger \mathrm{x}$ is the amino acid found in the published Erg11p sequence, NNN is the position in the ORF and $\mathrm{y}$ is the amino acid found in the isolate; if both alleles differ in sequence a slash is used to indicate this heterozygosity.

$\ddagger[\% \mathrm{C}] 1000 \mathrm{nM} / 100 \mathrm{nM}$ : percentage of control at a concentration of $1000 \mathrm{nM} / 100 \mathrm{nM}$.

\Despite several attempts and the addition of protease inhibitor, insufficient cytochrome P450 was isolated to test the sensitivity.

\| Mutations taken from Sanglard et al. (1998b).

to the reference sequence as shown in Table 1 . For the representation of the substitution we used the amino acid found in the reference sequence, followed by its position and the amino acid substitute found (all amino acids are designated by the conventional one-letter code). In total 12 different amino acid substitutions were identified. Six have already been reported: F72L (Ryder \& Favre, 1997), D116E (Kallakuri et al., 1996; Manavathu et al., 1996; Ryder \& Favre, 1997; Sanglard et al., 1998b ; Marr et al., 1998), K128T (Kallakuri et al., 1996; Manavathu et al., 1996; Löffler et al., 1997; Sanglard et al., 1998b), Y132H (Ryder \& Favre, 1997; Sanglard et al., 1998b; Okonogi et al., 1998), E266D (Kallakuri et al., 1996; Löffler et al., 1997; Ryder \& Favre, 1997) and G464S (Manavathu et al., 1996; Löffler et al., 1997; Sanglard et al., 1998b; Marr et al., 1998), but the other six were novel (A149V, D153E, E165Y, S279F, V452A and G465S). To verify our sequencing technique, we also included strain C26, for which the ERG11 sequence has been published (Sanglard et al., 1998b). All three mutations, D116E, Y132H and S405F, were confirmed as well as the other eight silent nucleotide changes, endorsing the validity of the sequencing analysis. Both sensitive reference strains, ATCC 28516 and ATCC 44858, contained an E266D variation. Strain ATCC 28516 was in addition heterozygous with respect to a phenylalanine/leucine substitution present on only one of its alleles, represented as F72F/L. Both alleles of strain ATCC 44858 carried a novel D153E mutation. Strains B59626 and B59630 were isolated from the same patient and their sequence was identical (in the 3 amino acid substitutions found as well as in 8 silent nucleotide changes) supporting the isogenicity of these strains, as was demonstrated by hybridization with the $\mathrm{Ca} 3$ repetitive probe (results not shown). The alanine/valine substitution $(\mathrm{A} 149 \mathrm{~V})$ in these strains has not been reported previously. Strain NCPF 3363 was the first strain for which Vanden Bossche et al. (1990) suggested a mutation in ERG11 based on biochemical evidence such as a diminished affinity for azole antifungals and a red shift in the maximum of the $\mathrm{CO}$ absorption spectrum from 448 to $450 \mathrm{~nm}$. This strain contained the previously identified $\mathrm{Y} 132 \mathrm{H}$ mutation on both of its ERG11 alleles and two heterozygotic substitutions S279S/F and G465G/S. The importance of this $\mathrm{Y} 132 \mathrm{H}$ mutation for azole susceptibility was demonstrated by Sanglard et al. (1998b). Strain J913004/1, isolated from an AIDS patient, contained four mutations, of which only V452A has not been reported previously. The laboratory mutant 6406/8 contained only one mutation, E165Y. This mutation was the result of a double nucleotide change in a single codon, GAA into TAC.

\section{Erg11p activity and sensitivity determination}

In recent papers, Lamb et al. (1997) and Sanglard et al. (1998) described elegant strategies to test for alterations in affinity of variant cytochrome P450 14-demethylases for azole derivatives. Both used heterologous expression in a $S$. cerevisiae host using a strong GAL promoter to overexpress the Candida Erg11p. In the Lamb et al. 
Table 2. Reported amino acid polymorphisms found in sensitive and resistant isolates and available characterization data

\begin{tabular}{|c|c|c|c|c|c|c|c|}
\hline \multirow[t]{2}{*}{ Strain } & \multirow[t]{2}{*}{ Reference } & \multirow{2}{*}{$\begin{array}{l}\text { Amino acid point mutation } \\
\qquad(\mathrm{xNNN} / \mathrm{y})^{*}\end{array}$} & \multicolumn{3}{|c|}{$\operatorname{MIC}\left(\mu \mathrm{g} \mathrm{ml}^{-1}\right)$} & \multicolumn{2}{|r|}{ ERG11 activity/sensitivity measurement } \\
\hline & & & Fluconazole & Itraconazole & Ratio & Method $\dagger$ & Conclusion \\
\hline 1 & White (1997) & & $0 \cdot 25$ & $0 \cdot 03$ & 8 & A & Flu-sensitive \\
\hline 17 & White (1997) & $\mathrm{R} 467 \mathrm{~K}$ & $>64$ & $>2$ & - & A & Flu $12 \times$ less active relative to strain 1 \\
\hline 1 & Marr et al. (1998) & D116E & $1 \cdot 25$ & 0.03 & 42 & A & Flu- and Itz-sensitive \\
\hline 5 & Marr et al. (1998) & D116E & 64 & $0 \cdot 3$ & 213 & A & Flu- and Itz-sensitive \\
\hline I1 & Löffler et al. (1997) & & 4 & 0.47 & 9 & ND & \\
\hline $\mathrm{I} 4$ & Löffler et al. (1997) & F105L & 128 & 0.064 & 2000 & ND & \\
\hline I7 & Löffler et al. (1997) & V488I & $>256$ & $>32$ & - & ND & \\
\hline I8 & Löffler et al. (1997) & E266D, G464S & $>256$ & $>32$ & - & ND & \\
\hline I12 & Löffler et al. (1997) & F105L, E266D & 8 & $0 \cdot 25$ & 32 & ND & \\
\hline TU1 & Löffler et al. (1997) & & 48 & 1 & 48 & ND & \\
\hline TU2 & Löffler et al. (1997) & & $>256$ & 0.75 & $>341$ & ND & \\
\hline TU3 & Löffler et al. (1997) & E266D, G448E & $>256$ & 4 & $>64$ & ND & \\
\hline TU4 & Löffler et al. (1997) & & 3 & $0 \cdot 125$ & 24 & ND & \\
\hline TU5 & Löffler et al. (1997) & & 64 & 0.75 & 85 & ND & \\
\hline TU6 & Löffler et al. (1997) & F105L, E266D & $>256$ & 6 & $>43$ & ND & \\
\hline TU7 & Löffler et al. (1997) & & 64 & 1 & 64 & $\mathrm{ND}$ & \\
\hline TU8 & Löffler et al. (1997) & & $>256$ & 1 & $>256$ & ND & \\
\hline TU9 & Löffler et al. (1997) & K287R, G464S & $>256$ & $>32$ & - & ND & \\
\hline P1 & Löffler et al. (1997) & & $>256$ & $>32$ & - & ND & \\
\hline P2 & Löffler et al. (1997) & F105L, G464S & $>256$ & $>32$ & - & ND & \\
\hline P3 & Löffler et al. (1997) & F105L, G450E & $>256$ & $0 \cdot 75$ & $>341$ & ND & \\
\hline P4 & Löffler et al. (1997) & G450E, V488I & $>256$ & $>32$ & - & ND & \\
\hline P5 & Löffler et al. (1997) & F105L & $>256$ & $>32$ & - & ND & \\
\hline FS10 & Löffler et al. (1997) & $\mathrm{K} 128 \mathrm{~T}$ & $0 \cdot 25$ & 0.5 & 0.5 & ND & \\
\hline FS19 & Löffler et al. (1997) & K147R & $0 \cdot 1$ & $0 \cdot 25$ & $0 \cdot 4$ & ND & \\
\hline ATCC 90028 & Okonogi et al. (1998) & & $\mathrm{Flu}^{\mathrm{s}}$ & $\mathrm{Itz}^{\mathrm{s}}$ & - & A & \\
\hline DUMC136 & Okonogi et al. (1998) & $\mathrm{Y} 132 \mathrm{H}, \mathrm{F} 145 \mathrm{~L}$ & $\mathrm{Flu}^{\mathrm{R}}$ & $\mathrm{ND}$ & - & A & Wild-type enzyme activity but Flu-resistant \\
\hline DC & Kallakuri et al. (1996) & D116E, K128T, K287R & $\mathrm{Flu}^{\mathrm{s}}$ & ND & - & ND & \\
\hline B312 & Kallakuri et al. (1996) & $\begin{array}{c}\text { D116E, K143R, E266D, R267H, } \\
\text { D278E }\end{array}$ & $\mathrm{Flu}^{\mathrm{R}}$ & ND & - & ND & \\
\hline PL01A & Manavathu et al. (1996) & D116E, K128T, G450E, G464S & $\mathrm{Flu}^{\mathrm{R}}$ & ND & - & ND & \\
\hline $\mathrm{C} 23$ & Sanglard et al. (1998b) & D116E, K128T, S405S/F & 1 & $0 \cdot 0625$ & 16 & B & $\begin{array}{l}\text { S405F allele; MIC increase for Flu }(4 \times) \text { and } \\
\text { for Itz }(2 \times)\end{array}$ \\
\hline C39 & Sanglard et al. (1998b) & S405F & 32 & $0 \cdot 125$ & 256 & B & MIC increase for Flu $(4 \times)$ and for Itz $(2 \times)$ \\
\hline $\mathrm{C} 33$ & Sanglard et al. (1998b) & D116E, E266Q, V437I & $0 \cdot 25$ & $0 \cdot 0312$ & 8 & $\mathrm{~B}$ & \\
\hline C34 & Sanglard et al. (1998b) & D116E, S405F & 2 & $0 \cdot 0625$ & 32 & $\mathrm{~B}$ & MIC increase for Flu $(4 \times)$ and for Itz $(2 x)$ \\
\hline $\mathrm{C} 26$ & Sanglard et al. (1998b) & D116E, Y132H, S405F & $>128$ & 4 & $>2 \cdot 0$ & $\mathrm{~B}$ & MIC increase for Flu $(>64 \times)$ and for Itz $(8 \times)$ \\
\hline $\mathrm{C} 82$ & Sanglard et al. (1998b) & D116E, S405F & 32 & 1 & 32 & $\mathrm{~B}$ & MIC increase for Flu $(4 x)$ and for Itz $(2 x)$ \\
\hline $\mathrm{C} 27$ & Sanglard et al. (1998b) & & 1 & $0 \cdot 0312$ & 32 & B & \\
\hline $\mathrm{C} 37$ & Sanglard et al. (1998b) & G464S, R467K & 8 & 0.0625 & 128 & B & MIC increase for Flu $(8 \times)$ and for Itz $(2 x)$ \\
\hline $\mathrm{C} 40$ & Sanglard et al. (1998b) & Y132Y/H, G464S, R467K & 128 & 1 & 128 & B & $\begin{array}{l}\text { Y132H allele; MIC increase for Flu }(>64 \times) \\
\text { and for Itz }(8 \times)\end{array}$ \\
\hline $\mathrm{C} 43$ & Sanglard et al. (1998b) & D116E, E266Q & $0 \cdot 25$ & $0 \cdot 0312$ & 8 & $\mathrm{~B}$ & \\
\hline $\mathrm{C} 56$ & Sanglard et al. (1998b) & D116E, G129A, G464S & 128 & $>2$ & - & $\mathrm{B}$ & $\begin{array}{l}\text { MIC increase for Flu }(32 \times) \text { and no increase for } \\
\text { Itz }\end{array}$ \\
\hline ATCC 64124 & Ryder \& Favre (1997) & F72L, Y132H, G450E & $>128$ & $>4$ & - & A & Flu-resistant \\
\hline NFI2007 & Ryder \& Favre (1997) & F126L, E266D, S405F, V437I & 32 & $0 \cdot 25$ & 128 & A & Flu-resistant \\
\hline NFI2013 & Ryder \& Favre (1997) & D116E, Y132H, F449L & $>128$ & $>4$ & - & A & Flu-resistant \\
\hline NFI2021 & Ryder \& Favre (1997) & K143E, T229A & $>128$ & 1 & $>128$ & A & Flu-resistant \\
\hline$-\ddagger$ & Lamb et al. (1997) & T315A & - & - & - & B & Enzyme less active, $5 \times$ less sensitive to Flu \\
\hline
\end{tabular}

ND, No data available.

* $\mathrm{x}$ is the amino acid found in the published Erg11p sequence, NNN is the position in the ORF and $\mathrm{y}$ is the amino acid found in the isolate; if both alleles differ in sequence a slash is used to indicate this heterozygosity.

† A, $\left[{ }^{14} \mathrm{C}\right]$ Mevalonic acid incorporation into sterols using a subcellular fraction. B, heterologous overexpression (gal promoter) of the cloned ERG11 in a S. cerevisiae host. Sensitivity was measured as an increase of MIC relative to the parent allele.

$\ddagger$ Mutation created by PCR.

(1997) system, the recombinant protein was purified and analysed with biochemical assays, whereas in the Sanglard et al. (1998b) method, affinity changes were directly correlated with changes in MIC values obtained with the engineered Saccharomyces strains. In this study we used biochemical assays with subcellular extracts prepared from the different isolates to look for the effects of different azole concentrations on either the incorporation of $\left[2-{ }^{14} \mathrm{C}\right]$ mevalonic acid into sterols or on the CO-complex formation of reduced microsomal cytochrome P450 fractions. Because two strains used in the Sanglard et al. (1998b) paper, C26 and C40, were included in this study, the results obtained with the different strategies could be compared.

The results obtained with the subcellular sterol bio- 
synthesis method are summarized in Table 1 . In the case of J913004/I and 6406/8, addition of PMSF to the homogenization buffer was found to be essential for enzyme activity, whereas no improvement was observed for the other isolates tested. For consistency reasons, PMSF was added to all preparations. According to the $\mathrm{IC}_{50}$ values obtained for itraconazole, only strain NCPF 3363 , previously reported to contain a mutated cytochrome P450 (Vanden Bossche et al., 1990), was less sensitive, having an $\mathrm{IC}_{50}$ value of $92 \mathrm{nM}$. All other isolates gave $\mathrm{IC}_{50}$ values in the range $14-40 \mathrm{nM}$ and as such can be regarded as itraconazole-sensitive. However, differences were seen at concentrations above the $\mathrm{IC}_{50}$ value, as shown in Table 1 . Indeed at $100 \mathrm{nM}$, a near complete inhibition was seen with the susceptible reference strains ATCC 28516 and ATCC 44858, and with isolates B59626, B59630 and J913004/I. A leaky ergosterol biosynthesis inhibition (14-24\% of control) at this concentration was seen with extracts from 6406/8, C26 and C40, suggestive of a decreased affinity for itraconazole. For fluconazole, more pronounced differences were observed. $\mathrm{IC}_{50}$ values ranged more than 100 -fold, from $41 \mathrm{nM}$ for the most sensitive isolate up to $4880 \mathrm{nM}$ for the C26 isolate. As well as in this C26 strain, reductions in affinity were seen for three other isolates, NCPF 3363, J913004/I and C40. Fluconazole was as active as itraconazole with regard to inhibition of subcellular sterol biosynthesis for both reference ATCC strains, whereas for all other azole-resistant strains tested, a 2.4- to 244-fold difference was observed in favour of itraconazole, suggesting that fluconazole binding is more sensitive to the amino acid variations present in these isolates. Incomplete inhibition of ergosterol biosynthesis was more pronounced with fluconazole because even at $1000 \mathrm{nM}$, isolates NCPF 3363, J913004/1, 6406/8, C26 and C40 still produced $16-78 \%$ of the amounts found in control conditions.

Prevention of CO-complex formation in the reduced microsomal cytochrome P450 preparations is another assay that can be used to test the affinity of the protein for an azole (Vanden Bossche et al., 1987; Yoshida, 1988). With this method, a constant content of $0 \cdot 1 \mathrm{nmol}$ cytochrome $\mathrm{P} 450 \mathrm{ml}^{-1}$ is used, enabling direct comparison of susceptibility between different isolates. Fluconazole was consistently found to be less active compared to itraconazole, even in the sensitive reference strains ATCC 28516 and ATCC 44858. Itraconazole was able to prevent $\mathrm{CO}$-cytochrome complex formation in all isolates from which an active extract could be isolated. For strains J913004/I and 6406/8 we consistently failed to obtain a fraction suitable for analysis. The addition of a protease inhibitor such as PMSF, or a protease inhibitor mix (leupeptin, PMSF, 4-amidinoPMSF) did not sufficiently improve the yield of active cytochrome P450. For the other strains, as seen in the sterol biosynthesis assays, differences were far more pronounced for fluconazole: $\mathrm{IC}_{50}$ values ranged almost 35 -fold from 140 to $5030 \mathrm{nM}$. Again, microsomes isolated from C26 and C40 showed the largest shifts, although the C40 microsomal fraction was the least sensitive in this assay. The cytochrome P450 isolated from NCPF 3363 was as sensitive as that isolated from susceptible strains.

\section{Computer-aided sequence analysis of identified mutations}

In Table 2 the published sequence variations of $C$. albicans ERG11 alleles are summarized next to the available growth sensitivity data. In total 53 full sequences were obtained, resulting in 98 variations relative to the Lai \& Kirsch (1989) sequence at 29 different locations, in addition to the PCR-induced T315A mutation reported by Lamb et al. (1997). This is a mean of 1.85 mutations per sequence. Because not all authors mention the silent nucleotide mutations found, a precise number of nucleotide changes cannot be given. For the seven strains sequenced in this study, 59 silent mutations were found (16 positions) compared to 18 amino acid changes (12 different), which suggests a three-fold higher frequency of silent mutations. To visualize the position and the frequency of the amino acids substitutions reported, a graphical representation was made (Fig. 1). At the top of the figure, the aligned sequences of the gene products of C. albicans ERG11 and that of the Pseudomonas putida CYP101 gene $\left(\mathrm{P} 450_{\text {cam }}\right)$ and their helical secondary structures are visualized. The alignment is taken from the model of Boscott \& Grant (1994). Gaps are represented as thin lines and predicted $\alpha$-helices are represented by boxes, for which the starting position and length are indicated. The letter code for the helices is indicated above the boxes. The mutations are represented by bars, for which the length is proportional to the frequency of occurrence. Different filling patterns are used to categorize the mutation: mutations found both in azole-sensitive and -resistant strains are represented by open bars and are probably not important for azole affinity. These substitutions could reflect allelic or strain variation. A filled bar is used for the mutations experimentally demonstrated to be important for the affinity of an azole for cytochrome P450. Non-characterized mutations are shown represented by hatched bars. The PCR-induced mutation is represented by an arrow. From Fig. 1 it is clear that the majority of the mutations were found in three regions: region 1 from amino acids 105 to 165 , region 2 from 266 to 287 and region 3 from 405 to 488 . This last region also contains $\mathrm{C}_{470}$, the fifth ligand of the haem. Three of the four mutations found with the highest frequency, D116E, K128T and E266D, were also found in azole-sensitive strains; only G464S has been seen exclusively in resistant strains. No spontaneous mutation was found in the I helix, which is highly conserved over the 14-demethylase cytochrome P450 family.

A molecular three-dimensional model of C. albicans Erg11p was proposed by Boscott \& Grant (1994; coordinates are available from these authors) after homology modelling onto the bacterial crystal structure of Cyp101p. In Fig. 2 views from two different 


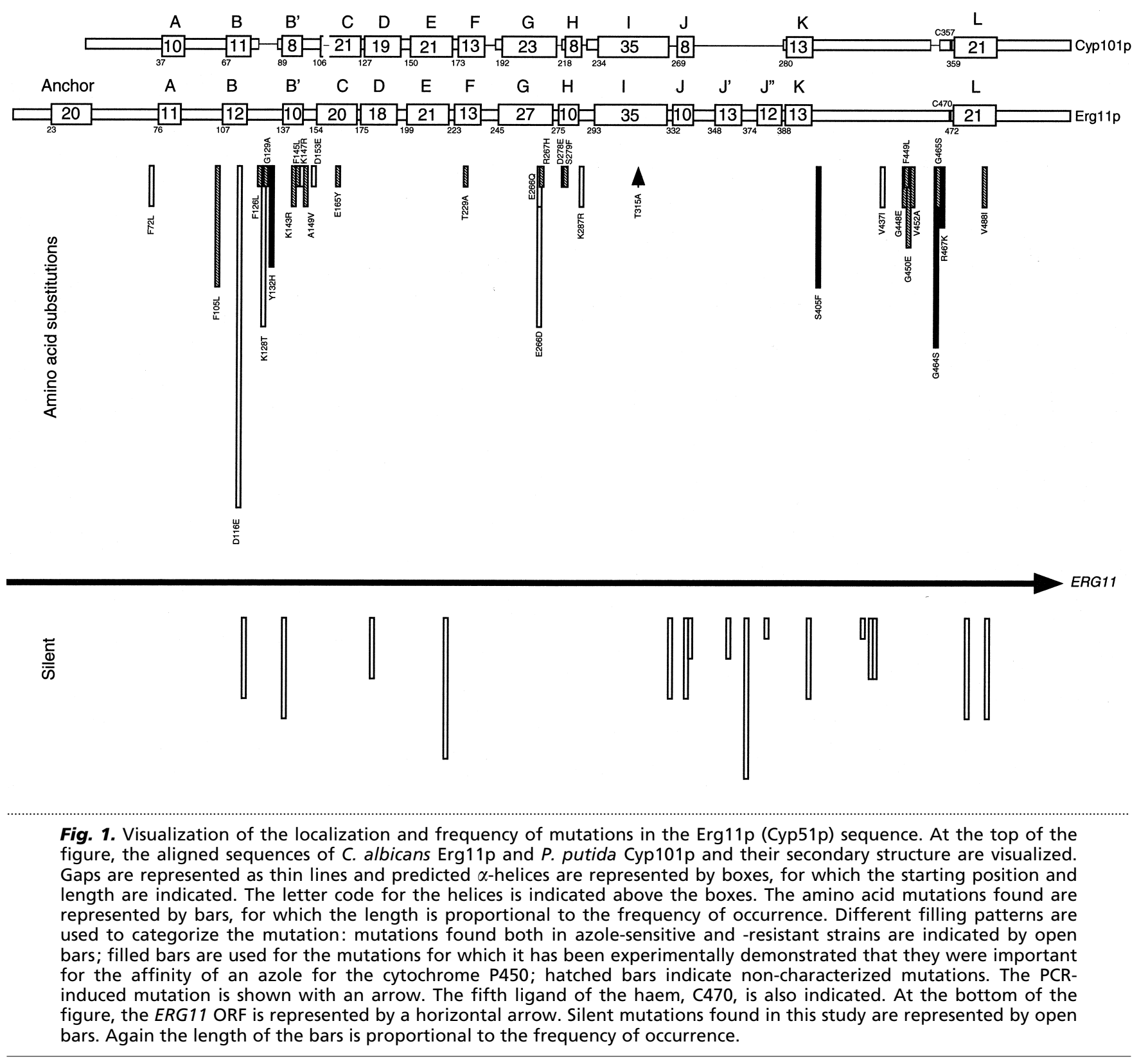

angles are given of the ribbon model. The haem is shown in green and, as an orientation aid, the central I helix is represented in orange. Because of the projection onto the plane of the paper, localization of the mutations can be misleading. To circumvent these optical artefacts, stereo views were included to allow a more precise 3D localization. The mutations discussed in this paper are placed onto this ribbon model as solid spheres with a diameter of the Van der Waals interaction range of a carbon atom. The substitutions are again categorized according to the same principle as in Fig. 1, however, a colour code is used in this model; substitutions found in both azole-sensitive and -resistant Erg11p are represented by blue spheres, substitutions experimentally demonstrated to be important for azole affinity are shown in red, non-characterized mutations are shown in black and the PCR-induced mutation is shown in green. The cytochrome P450 Erg11p catalyses the oxidative removal of the 14-methyl-group of ergosterol precursors. The prosthetic haem molecule is positioned between the proximal I helix and the distal L helix in the inner part of the enzyme as is shown in Fig. 2. This necessitates both the entry and positioning of the substrate such that its 14-methyl group is in close proximity to the activated sixth ligand of the central haem. This suggests that the substrate should position below the I helix and proximal to the haem. Because in this model no access channel is found of sufficient size to enable entry and exit of the substrate, it is hypothesized that some movement of the $\mathrm{B}^{\prime}$ helix and/or the coil between the $F$ and $G$ helices is necessary for the entry. However, because of poor sequence similarity in this 

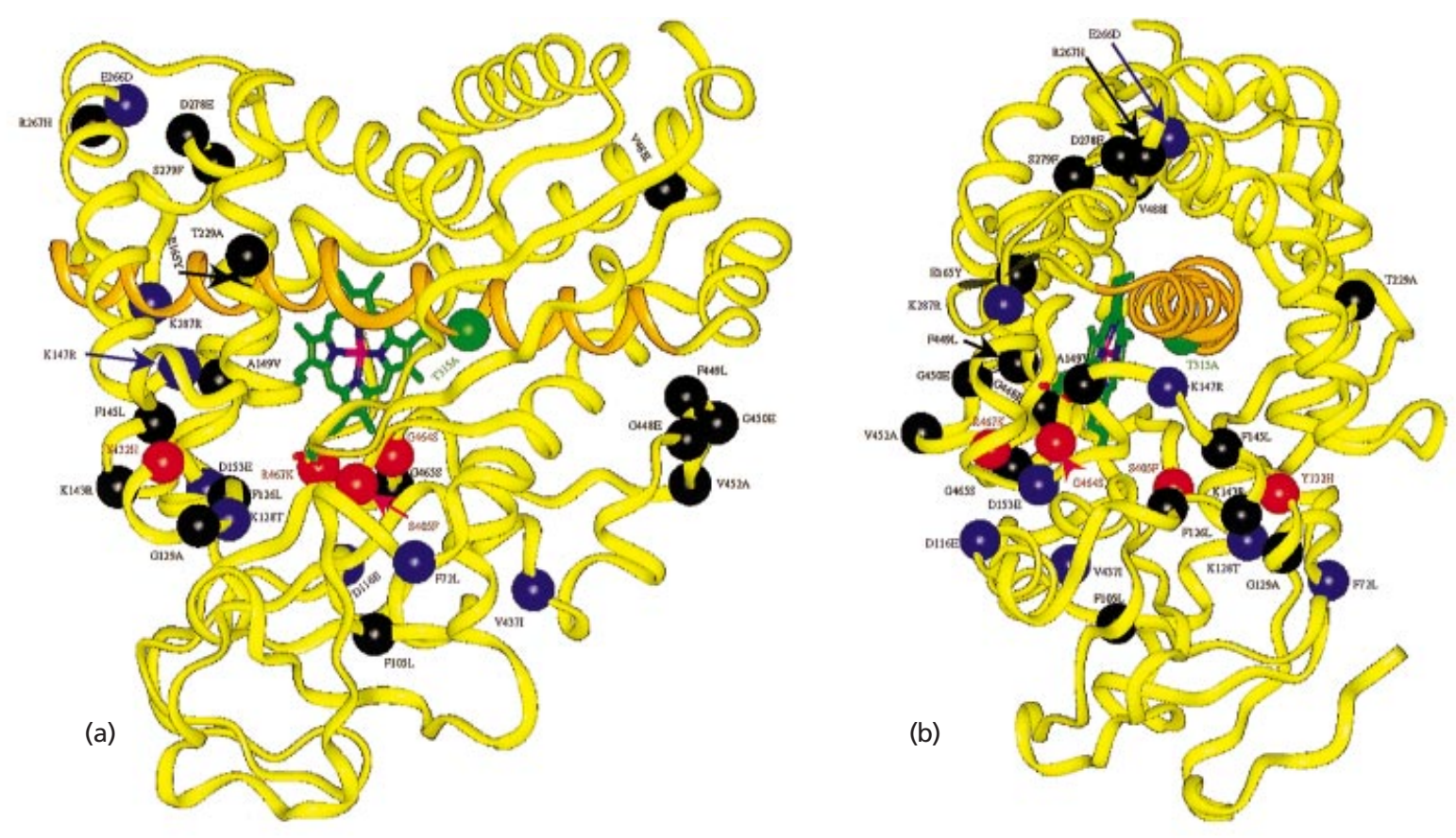

(c)
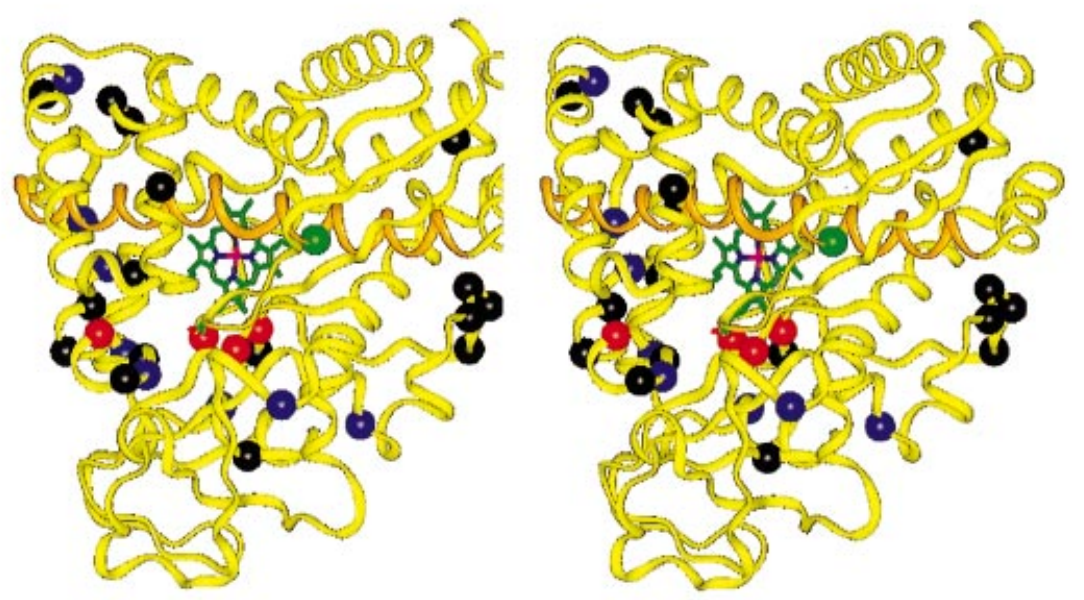

(d)
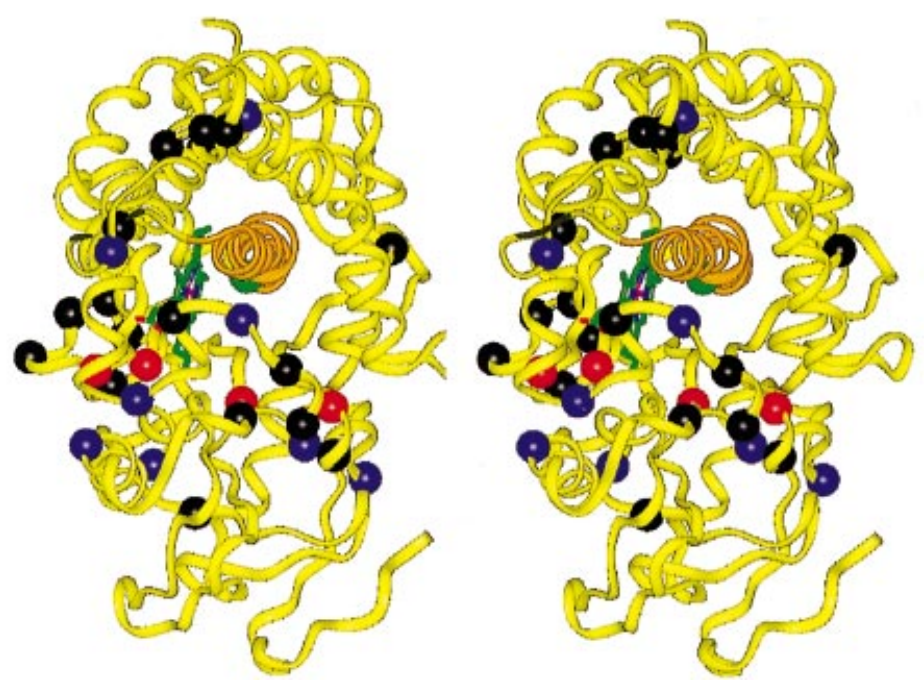


\section{Table 3. Sequence comparison of the 19 different 14-demethylases}

The sequences were aligned with CLUSTAL w. Identified amino acid substitutions found in C. albicans are shown. Amino acids identical to C. albicans are represented by a dot. Highly conserved amino acids are in bold type. '-' is indicative of a gap in the sequence alignment. The full length alignment is available on request. Amino acid numbering is taken from the C. albicans sequence.

Organism

Candida albicans

Saccharomyces cerevisiae

Candida glabrata

Candida tropicalis

Candida krusei

Candida parapsilosis*

Candida guilliermondii*

Candida kefyr"

Pichia anomalia*

Schizosaccharomyces pombe

Penicillium italicum

Ustilago maydis

Uncinula necator

Pig

Rat

Human

Sorghum bicolor

Triticum aestivum

Arabidopsis thaliana

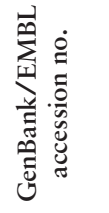

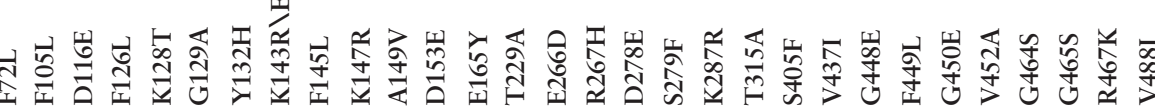

*Partial sequence available.

region between the fungal sequences and the bacterial models, no precise entry point can be identified. The antifungal azoles are believed to enter through the same access channel and inhibit cytochrome P450 by binding with their unprotonated $\mathrm{N}$ atom to the sixth coordination site of the haem and occupy the substratebinding pocket (Vanden Bossche \& Koymans, 1997). An important factor of the stability and specificity of the binding of different azoles originates from the interaction of the N1 ligand moiety of the azole with the apoprotein. Mutations in the protein could alter the affinity for an azole by interference with the entry of the azole or could change interaction points either directly or indirectly by a repositioning of the tertiary structure through changes in the positions of the structural helices as was demonstrated by the G310D mutation in $S$. cerevisiae Erg11p (Vanden Bossche \& Koymans, 1997). The substitutions F126L, K128T, G129A, Y132H, K143R, F145L and K147R are close to this access channel and could interfere with the entry of the inhibitor. The G464S, G465S and R467K mutations are positioned behind the plane of the haem. The G465S and R467K mutations are probably too far away from the haem to interfere directly with the interaction of the azoles but G464S is in very close proximity. The S405F substitution is positioned just after the $\mathrm{K}$ helix and is close to the substrate and azole-binding pocket. Mutations E266D, R267H, D278E and S279F are located at the end of the G helix and the start of the $\mathrm{H}$ helix on the surface of the protein. This region could act as a pivot for the G- and F-helices to enlarge the access channel. Mutation T229A is on the F helix, but rather distant from the I helix. The V488I substitution is found at the end of the L helix. The four mutations G448E, F449L, G450E and V452A are close to the site where the I helix ends. No mutations are seen in the bottom part of the protein below the F105L mutation. This region of the protein is likely to be buried into the membrane.

Fig. 2. Ribbon presentation of the three-dimensional model of $C$. albicans Cyp51p structure from two different viewpoints $(a$ and $b)$. The central I helix is shown in orange, the haem is shown in green. The mutations described in this study are marked by spheres and are categorized according to the same principle as in Fig. 1; however, a colour code is used in this model; substitutions found in both azole-sensitive and -resistant strains are represented by blue spheres, substitutions experimentally demonstrated to be important for azole affinity are shown in red, non-characterized mutations are shown in black and the PCR-induced mutation is shown in green. To allow a more precise spatial localization, stereo pictures of both views are shown in (c) and (d). 
It is likely that an amino acid that is important for azole interaction is conserved in the Erg11p sequences from other sensitive species. To investigate this, we first aligned all 19 known sterol 14-demethylases (13 fungal Erg11p sequences, three mammalian Cyp51p sequences and three plant Cyp51p sequences) using the CLUSTAL w multiple alignment algorithm. Table 3 lists the aligned amino acids obtained for all 29 identified mutations. The full sequence alignment is available from the corresponding author upon request. Only three amino acids were conserved for all available 14DM sequences, F126, G464 and R467. If the plant sequences were excluded, K143, K147 and E165 are conserved across the fungal and mammalian Cyp51p sequences and amino acids F145, G448, and G450 are conserved across all fungal Cyp51p sequences. Among the amino acid substitutions found in azole-sensitive strains, D116E, D153E, E266D and V437I vary even among the yeast sequences, as do the non-characterized F105L, R267H, S279F, V452A and V488I substitutions. It is therefore unlikely that these substitutions are on their own important for azole binding.

\section{DISCUSSION}

Strain 6406/8 has been described as azole-resistant but this could not be confirmed in this study. The different conditions in which sensitivity was measured could be responsible for this discrepancy. Another possibility is that long-term storage and/or distribution of the isolate to different laboratories has resulted in changes. Indeed, a similar phenomenon was demonstrated for the Darlington strain, for which isolates obtained from different locations were found to behave differently with regard to their sensitivity and small variations were seen in their restriction fragment length polymorphism (RFLP) patterns (Pearce \& Howell, 1991). It is unlikely that the double nucleotide change found in a single codon was introduced at the same time. If the first mutation event was GAA to TAA, this would introduce a stop codon interrupting the translation process. After homologous recombination, this would result in a 14demethylase-deficient strain as reported by Hitchcock et al. (1987). The subsequent introduction of a second mutation, TAA to TAC, would be advantageous for the isolate because it would restore the transcription of the full length of the ORF and 14-demethylase activity. The 14-demethylase deficiency reported could, however, also originate from the absence of a protease inhibitor in the enzyme preparation procedure, because we found such an addition necessary for enzyme activity. To verify the different hypotheses we would need access to the different subcultured specimens from the original 6406/8 strain.

Three different methods are available to investigate the affinity of cytochrome P450 for an azole inhibitor and each method has its strengths and limitations. The CObinding assay is very easy to perform and allows immediate comparison between different isolates because a standard amount of cytochrome P450 is used. A drawback of this method is that preparations must be made from strains growing in high glucose and with oxygen limitation. Moreover, the preparation could contain non-14-demethylase cytochrome P450 and the long preparation time needed to obtain the washed microsomal preparation increases exposure to proteolysis. The subcellular ergosterol bioassay requires less preparation and as such is less sensitive to proteolysis. With both of these methods the enzymes are in their natural Candida membrane environment. This is in contrast with the third method: heterologous expression in $S$. cerevisiae. This heterologous expression method allows measurements of single allele products but because of differences in preferred codon usage between Candida and Saccharomyces could also introduce contributions from silent mutations. The use of a strong GAL promoter could also introduce unnaturally high concentrations of the cytochrome. Indeed Lamb et al. (1997) found concentrations of $2.5 \mathrm{nmol}$ microsomal protein $\mathrm{mg}^{-1}$, at least 25 times the basal level. This huge overexpression of membrane-bound protein forces cells to hyperproliferate their membranes, which often form multilamellar membrane structures around the nucleus (karmella) (Vergeres et al., 1993; Supply et al., 1993). It is therefore not surprising that the results obtained with the three methods do not match perfectly. The C26 Erg11p variant has a lower affinity for fluconazole according to all three methods. In contrast, the eightfold decrease in affinity for itraconazole suggested by the heterologous expression system was not confirmed by $\mathrm{CO}$ binding or by a decrease in $\mathrm{IC}_{50}$ in the subcellular assay. The incomplete enzyme inhibition at $100 \mathrm{nM}$ itraconazole observed in the subcellular assay could, however, be of importance because for growth inhibition in C. albicans a depletion of ergosterol is needed. If a leaky inhibition is sufficient for resistance, then four out of nine isolates (NCPF 3363, 6406/8, C26 and $\mathrm{C} 40$ ) could be regarded as itraconazole-refractory and in the case of fluconazole isolate J913004/1 is also resistant. These criteria suggest that the E165Y mutation found in the laboratory mutant interferes with both itraconazole and fluconazole binding. To demonstrate this, the E165Y mutation should be introduced by mutagenesis; if one envisages heterologous expression in a Saccharomyces host, one should moreover prevent the unintended S263L mutation resulting from the different translation of the CUG codon in Candida versus Saccharomyces. Three other refractory alleles contain the $\mathrm{Y} 132 \mathrm{H}$ substitution, corroborating its importance. As suggested by Sanglard et al. (1998b) a concomitant substitution of S405F or R467K further decreases affinity, especially for fluconazole. The smaller, hydrophilic fluconazole molecule has fewer stabilization sites in the active pocket compared to the lipophilic itraconazole molecule which may explain this difference in activity (Vanden Bossche \& Koymans, 1997). Moreover, because the CO-binding assay did not reveal a diminished sensitivity for the NCPF 3363 isolate (having a homozygotic Y132H substitution), it is likely 
that a concomitant mutation is necessary for maximal effect. In this isolate, the originally reported shift in CObinding sensitivity (Smith et al., 1986), comparable to that found in the C26 and C40 isolates for fluconazole, could not be reproduced on later occasions; this could be due to loss of a second mutation on one or on both alleles. Unfortunately, the isolate possessing the original phenotype could not be retrieved to investigate this hypothesis.

The sequence available for Candida guilliermondii Erg11p also contained a phenylalanine aligning with S405 from C. albicans. Because different C. guilliermondii isolates tend to vary substantially in their fluconazole susceptibility (Odds, 1992), it would be interesting to know the MIC of fluconazole for the isolate used for sequencing and to verify whether the presence of that phenylalanine correlates with higher fluconazole MIC values. From the substitutions identified in the J913004/I isolate, D116E and K128T probably do not contribute to the decrease in fluconazole activity because these substitutions were also found in multiple azole-sensitive strains. In fact, it is likely that all substitutions found in azole-sensitive strains, and presumably also a selection of the non-characterized substitutions found only in resistant strains so far, reflect strain variation. From the substitutions found in the N-terminal and central region of the protein, only $\mathrm{Y} 132 \mathrm{H}$ was associated with resistance. In these regions a higher proportion of the substitutions was also found in azole-sensitive strains when compared to the Cterminal region. No spontaneous substitutions have been found so far in the very conserved central I helix. A reason for this could be that substitutions in this region induce loss of function of the enzyme that would result in slower growth rates and therefore would be disadvantagous for survival. Such a mutation, G310D, has been described in S. cerevisiae (Ishida et al., 1988). The C-terminal part contains three substitutions associated with resistance, and from the remaining substitutions only one was found in azole-sensitive strains. This region therefore looks to be of greater importance for azole resistance. Further study is needed to verify to what extent V452A and G464S mutations contribute to resistance. The fact that G464S was found by several investigators in azole-resistant strains makes this a prioritized substitution for investigation. The V452A substitution, as well as the G448E, F449L and G450E mutations are situated near the end of the central I helix and the J helix, an area of the protein that could be important for the docking of cytochrome P450 reductase. Indeed it is hypothesized that this region, which is absent in the Cyp101 sequence, and as such also in the model, is creating the recognition and docking site for the reductase. It has to be stressed that the threedimensional model used is based on a soluble isozyme of bacterial origin, with different substrate specificity. For this reason, only approximate locations of the mutations can be given. The Mycobacterium tuberculosis CYP51like gene, identified by in silico analysis of the full genome, could become a better model because this soluble enzyme could 14-demethylate dihydrolanosterol but crystallization and structure determination has not been achieved yet (Aoyama et al., 1998; Bellamine et al., 1998). The availability of multiple sequences of Erg11p from Candida krusei, a species with a $14 \alpha$-demethylase less susceptible to azoles (Marichal et al., 1995; Orozco et al., 1998) could provide additional comparative material to identify important regions for binding of azoles to the cytochrome P450.

\section{ACKNOWLEDGEMENTS}

We thank B. Dupont (Paris, France), D. Sanglard (Lausanne, Switzerland), G. Just (Frankfurt, Germany) and D. Kerridge (Cambridge, UK) for the supply of isolates, L. Leijssen, I. Beyens, T. Verhulst, E. Nijenhuis and L. Van Nuffel for their excellent technical skills and I. Moelans for interesting discussions.

\section{REFERENCES}

Aoyama, Y., Horiuchi, T., Gotoh, O., Noshiro, M. \& Yoshida, Y. (1998). CYP51-like gene of Mycobacterium tuberculosis actually encodes a P450 similar to eukaryotic CYP51. J Biochem 124, 694-696.

Bard, M., Lees, N. D., Turi, T., Craft, D., Cofrin, L., Barbuch, R., Koegel, C. \& Loper, J. C. (1993). Sterol synthesis and viability of ERG11 (cytochrome P450 lanosterol demethylase) mutations in Saccharomyces cerevisiae and Candida albicans. Lipids 28, 963-967.

Bellamine, A., Mangla, A. T., Nes, D. \& Waterman, M. R. (1998). Is the Mycobacterium tuberculosis CYP51-like P450 a $14 \alpha-$ demethylase? In Program and Abstracts of the Fourth International Symposium on P450 Biodiversity and Biotechnology, Strasbourg, France. IC-11.

Bodey, G. P. (1997). Resistance to antimicrobial agents revisited. Curr Opin Infect Dis 10, 419-421.

Boscott, P. E. \& Grant, G. H. (1994). Modeling cytochrome P450 $14 \alpha$-demethylase (Candida albicans) from P450cam. J Mol Graph 12, 185-192.

Bradford, M. M. (1976). A rapid and sensitive method for the quantitation of microgram quantities of protein utilizing the principle of protein-dye binding. Anal Biochem 72, 248-254.

Cartledge, J. D., Midgley, J. \& Gazzard, B. G. (1997). Clinically significant azole cross-resistance in Candida isolates from HIVpositive patients with oral candidosis. AIDS 11, 1839-1844.

De Muri, G. P. \& Hostetter, M. K. (1995). Resistance to antifungal agents. Pediatr Clin N Am 42, 665-685.

Denning, D. W., Baily, G. G. \& Hood, S. V. (1997). Azole resistance in Candida. Eur J Clin Microbiol Infect Dis 16, 261-280.

Doignon, F., Aigle, M. \& Ribereau-Gayon, P. (1993). Resistance to imidazoles and triazoles in Saccharomyces cerevisiae as a new dominant marker. Plasmid 30, 224-233.

Dupont, B. (1995). Azole antifungal agents : emerging and inherent resistance. Curr Opin Infect Dis 8, 424-427.

Frosco, M. \& Barrett, J. F. (1998). Importance of antifungal drugresistance: clinical significance and need for novel therapy. Exp Opin Invest Drugs 7, 175-198.

Hartman, P. G. \& Sanglard, D. (1997). Inhibitors of ergosterol as antifungal agents. Curr Pharm Des 3, 177-208.

Hitchcock, C. A., Russell, N. J. \& Barrett-Bee, K. J. (1987). Sterols 
in Candida albicans mutants resistant to polyene or azole antifungals, and of a double mutant C. albicans 6.4. Crit Rev Microbiol 15, 111-115.

Ishida, N. Y., Aoyama, Y., Hatanaka, R. \& 10 other authors (1988). A single amino substitution converts cytochrome $\mathrm{P}^{4} 50_{14 \mathrm{dm}}$ to an inactive form, cytochrome $\mathrm{P} 450_{\mathrm{SG} 1}$ : complete primary structure deduced from cloned DNAs. Biochem Biophys Res Commun 155, 317-323.

Johnson, E. M. \& Warnock, D. W. (1995). Azole drug resistance in yeast. J Antimicrob Chemother 36, 751-755.

Joseph-Horn, T. \& Hollomon, D. W. (1997). Molecular mechanisms of azole resistance in fungi. FEMS Microbiol Lett 149, 141-149.

Kallakuri, S., Manavathu, E. K., Arganoza, M. T., Vazquez, J. A. \& Sobel, J. D. (1996). Molecular characterization of the gene encoding cytochrome P450-dependent lanosterol $14 \alpha$ demethylase from a fluconazole-resistant clinical isolate of Candida albicans. In Program and Abstracts of the 96 th American Society for Microbiology General Meeting, New Orleans, Louisiana, 1996, Abstract F-63, p. 84. Washington, DC: American Society for Microbiology.

Kelly, S. L., Lamb, D. C., Kelly, D. E., Manning, N. J., Loeffler, J., Schumacher, H. U. \& Einsele, H. (1997). Resistance to fluconazole and cross-resistance to amphotericin B in Candida albicans from AIDS patients caused by defective sterol delta 5,6-desaturation. FEBS Lett 400, 80-82.

Kolaczkowski, M. \& Goffeau, A. (1997). Active efflux by multidrug transporters as one of the strategies to evade chemotherapy and novel practical implications of yeast pleiotropic drug resistance. Pharmacol Ther 76, 219-242.

Lai, M. H. \& Kirsch, D. R. (1989). Nucleotide sequence of cytochrome P450 L1A1 (lanosterol $14 \alpha$ demethylase) from Candida albicans. Nucleic Acids Res 17, 804.

Lamb, D. C., Kelly, D. E., Schunck, W.-H., Shyadehi, A. Z., Akhtar, M., Lowe, D., Baldwin, B. C. \& Kelly, S. L. (1997). The mutation T315A in Candida albicans sterol $14 \alpha$-demethylase causes reduced enzyme activity and fluconazole resistance through reduced affinity. J Biol Chem 272, 5682-5688.

Löffler, J., Kelly, S. L., Hebart, H., Schumacher, U., Lass-Flörl, C. \& Einsele, H. (1997). Molecular analysis of cyp51 from fluconazoleresistant Candida albicans strains. FEMS Microbiol Lett 151, 263-268.

Manavathu, E. K., Kallakuri, S., Arganoza, M. T., Pierson, C. \& Vazquez, J. A. (1996). Amino acid variations of cytochrome P450dependent lanosterol $14 \alpha$-demethylase (P450LDM) from a fluconazole-resistant clinical isolate of Candida albicans. In Program and Abstracts of the 36th Interscience Conference on Antimicrobial Agents and Chemotherapy, New Orleans, Louisiana, 1996, Abstract C68, p. 46. Washington, DC: American Society for Microbiology.

Marichal, P. \& Vanden Bossche, H. (1995). Mechanisms of resistance to azole antifungals. Acta Biochim Pol 42, 509-516.

Marichal, P., Gorrens, J., Coene, M.-C., Le Jeune, L. \& Vanden Bossche, H. (1995). Origin of differences in susceptibility of Candida krusei to azole antifungal agents. Mycoses 38, 111-117.

Marichal, P., Vanden Bossche, H., Odds, F. C., Nobels, G., Warnock, D. W., Timmerman, V., Van Broeckhoven, C., Fay, S. \& Mose-Larsen, P. (1997). Molecular biological characterization of an azole-resistant Candida glabrata isolate. Antimicrob Agents Chemother 41, 2229-2237.

Marr, K. A., Lyons, C. N., Rustad, T., Bowden, R. A. \& White, T. C. (1998). Rapid, transient fluconazole resistance in Candida albicans is associated with increased mRNA levels of CDR. Antimicrob Agents Chemother 42, 2584-2589.

National Committee for Clinical Laboratory Standards (1995). Reference method for broth dilution susceptibility testing of yeasts. Tentative standard M27-A. Villanova, PA: National Committee for Clinical Laboratory Standards.

Odds, F. C. (1992). Antifungal susceptibility testing of Candida spp. by relative growth measurement at single concentrations of antifungal agents. Antimicrob Agents Chemother 36, 1727-1737. Odds, F. C. (1998). Should resistance to azole antifungals in vitro be interpreted as predicating clinical non-response? Drug Res Updates 1, 11-15.

Odds, F. C., Vranckx, L. \& Woestenborghs, F. (1995). Antifungal susceptibility testing of yeasts: Evaluation of technical variables for test automation. Antimicrob Agents Chemother 39, 2051-2060.

Okonogi, K., Asia, K., Tsuchimori, N., Perfect, J. R., Gotoh, O. \& Yoshida, Y. (1998). A novel mechanism for emerging azoleresistant Candida albicans in AIDS patients. In Program and Abstracts of the Fourth International Symposium on P450 Biodiversity and Biotechnology, Strasbourg, France.

Orozco, A. S., Higginbotham, L. M., Hitchcock, C. A., Parkinson, T., Falconer, D., Ibrahim, A. S., Ghannoum, M. A. \& Filler, S. G. (1998). Mechanism of fluconazole resistance in Candida krusei. Antimicrob Agents Chemother 42, 2645-2649.

Pearce, M. A. \& Howell, S. A. (1991). Restriction fragment length polymorphism analysis of azole-resistant and azole-susceptible Candida albicans strains. J Clin Microbiol 29, 1364-1367.

Rex, J. H., Rinaldi, M. G. \& Pfaller, M. A. (1995). Resistance of Candida species to fluconazole. Antimicrob Agents Chemother 39, 1-8.

Rodriguez, R., Low, C., Bottema, C. \& Parks, L. (1985). Multiple functions for sterols in Saccharomyces cerevisiae. Biochim Biophys Acta 837, 336-343.

Ryder, N. S. \& Favre, B. (1997). Resistance to azoles in Candida albicans caused by mutations in the lanosterol $14 \alpha$-demethylase gene. In Program and Abstracts of the 37th Interscience Conference on Antimicrobial Agents and Chemotherapy, Toronto, Canada, 1997, Abstract C-13, p. 48. Washington, DC: American Society for Microbiology.

Sanglard, D., Kuchler, K., Ischer, F., Pagani, J. L., Monod, M. \& Bille, J. (1995). Mechanisms of resistance to azole antifungal agents in Candida albicans isolates from AIDS patients involve specific multidrug transporters. Antimicrob Agents Chemother 39, 2378-2386.

Sanglard, D., Ischer, F., Calabrese, D., de Micheli, M. \& Bille, J. (1998a). Multiple resistance mechanisms to azole antifungals in yeast clinical isolates. Drug Res Updates 1, 255-265.

Sanglard, D., Ischer, F., Koymans, L. \& Bille, J. (1998b). Amino acid substitutions in the cytochrome P450 lanosterol 14alphademethylase (CYP51) from azole-resistant Candida albicans clinical isolates contributing to the resistance to azole antifungal agents. Antimicrob Agents Chemother 42, 241-253.

Smith, K. J., Warnock, D. W., Kennedy, C. T. C., Johnson, E. M., Hopwood, V., Van Cutsem, J. \& Vanden Bossche, H. (1986). Azole resistance in Candida albicans. J Med Vet Mycol 24, 133-144.

Supply, P., Wach, A., Thines-Sempoux, D. \& Goffeau, A. (1993). Proliferation of intracellular structures upon overexpression of the PMA2 ATPase in Saccharomyces cerevisiae. J Biol Chem 268, 19744-19752.

Vanden Bossche, H. (1997). Mechanisms of antifungal resistance. Rev Iberoam Micol 14, 44-49. 
Vanden Bossche, H. \& Koymans, L. (1997). Cytochromes P450 in fungi. Mycoses 41, (suppl. 1) 32-38.

Vanden Bossche, H., Willemsens, G., Cools, W., Cornelissen, F., Lauwers, W. F. \& Van Cutsem, J. M. (1980). In vitro and in vivo effects of the antimycotic drug ketoconazole on sterol synthesis. Antimicrob Agents Chemother 17, 922-928.

Vanden Bossche, H., Bellens, D., Cools, W. \& 10 other authors (1986). Cytochrome P-450: target for itraconazole. Drug Dev Res 8, 287-298.

Vanden Bossche, H., Marichal, P., Gorrens, J., Bellens, D., Verhoeven, H., Coene, M.-C., Lauwers, W. \& Janssen, P. W. J. (1987). Interaction of azole derivatives with cytochrome P-450 isozymes in yeast, fungi, plants and mammalian cells. Pestic Sci 21, 1-13.

Vanden Bossche, H., Marichal, P., Gorrens, J., Bellens, D., Moereels, H. \& Janssen, P. A. J. (1990). Mutation in cytochrome P450-dependent $14 \alpha$-demethylase results in decreased affinity for azole antifungals. Biochem Soc Trans 18, 56-59.

Vanden Bossche, H., Marichal, P., Odds, F. C., Le Jeune, L. \& Coene, M.-C. (1992). Characterization of an azole-resistant Candida glabrata isolate. Antimicrob Agents Chemother 36, 2602-2610.

Vanden Bossche, H., Marichal, P. \& Odds, F. C. (1994). Molecular mechanisms of drug resistance in fungi. Trends Microbiol 2, $393-400$.
Vanden Bossche, H., Dromer, F., Improvisi, L., Lozano-Chiu, M., Rex, J. H. \& Sanglard, D. (1998). Antifungal drug resistance in pathogenic fungi. Med Mycol 36, (suppl. 1) 119-128.

Vergeres, G., Yen, T. S., Aggeler, J., Lausier, J. \& Waskell, L. (1993). A model system for studying membrane biogenesis. Overexpression of cytochrome b5 in yeast results in marked proliferation of the intracellular membrane. J Cell Sci 106, 249-259.

Watson, P. F., Rose, M. E., Ellis, S. W., England, H. \& Kelly, S. L. (1989). Defective sterol C5-6 desaturation and azole resistance: a new hypothesis for the mode of action of azole antifungals. Biochem Biophys Res Commun 164, 1170-1175.

White, T. C. (1997). The presence of an R467K amino acid substitution and loss of allelic variation correlate with an azoleresistant lanosterol $14 \alpha$-demethylase in Candida albicans. Antimicrob Agents Chemother 41, 1488-1494.

White, T. C., Bowden, R. A. \& Marr, K. A. (1998). Clinical, cellular and molecular factors that contribute to antifungal drug resistance. Clin Microbiol Rev 11, 382-402.

Yoshida, Y. (1988). Cytochrome P450 of fungi, primary target for azole antifungal agents. Curr Top Med Mycol 2, 388-418.

Received 15 March 1999; revised 28 May 1999; accepted 10 June 1999 